\title{
Comparison of the diagnostic value of histopathological examinations of miscarriage products after pharmacological induction of miscarriage and curettage
}

\author{
Jakub Sliwa ${ }^{1}$, Anna Kryza-Ottou ${ }^{1}$, Anna Rosner-Tenerowicz ${ }^{1}$, \\ Maciej Kaczorowski ${ }^{2}$, Mariusz Zimmer ${ }^{1}$, Zygmunt Domagala ${ }^{3}$ \\ ${ }^{1}$ Medical University of Wroclaw, Departament of Obstetrics and Gynecology, Wroclaw, Poland \\ ${ }^{2}$ Department of Pathomorphology and Oncological Cytology, Wroclaw Medical University, Wroclaw, Poland \\ ${ }^{3}$ Department of Anatomy, Morphology and Human Embryology, Wroclaw Medical University, Wroclaw, Poland
}

\begin{abstract}
Objectives: For early miscarriage (pregnancy loss $\leq 12$ weeks of gestation), two types of therapeutic treatment are offered (pharmacotherapy and curettage of the uterine cavity) depending on the presence and severity of clinical symptoms as well as patient choice. Our study aimed to assess the diagnostic value of the results of histopathological examinations of miscarriage products in relation to the administered treatments.

Material and methods: 850 medical records from patients diagnosed with missed miscarriage or empty gestational sac were analyzed retrospectively. Patients underwent surgical treatment or pharmacotherapy. Inefficacy of pharmacotherapy resulted in subsequent curettage. The results of histopathology were evaluated for their diagnostic value and classified: subgroup 1 - high value specimen (the studied specimen included fetal tissues, and villi), and subgroup 2 - no-diagnosis (the studied specimen included maternal tissues, autolyzed tissues, blood clots). Data were compared with chi-squared test. Differences was considered significant at $p<0.05$.

Results: 1128 histopathological test results were analyzed; 569 (50.4\%) were obtained during pharmacotherapy and $559(49.6 \%)$ after curettage; out of the latter 497 after the initial pharmacotherapy and 62 after surgery. In the pharmacotherapy group, high value specimens comprised 231 cases (40.59\%) while no diagnosis was obtained in 338 cases (59.4\%). Considering specimens obtained in the course curettage, high value specimens were found in 364 cases (65.1\%) while results that did not allow a diagnosis to be made were found in 195 cases (34.9\%).

Conclusions: Tissue specimens of high diagnostic value are obtained significantly more often during surgical treatment of miscarriage than during pharmacotherapy.

Key words: curettage; miscarriage; spontaneous abortion; histology; differential diagnosis
\end{abstract}

Ginekologia Polska 2019; 90, 6: 331-335

\section{INTRODUCTION}

Early miscarriage is a term used to describe the loss of pregnancy within the first 12 weeks of gestation. This diagnosis concerns $10-15 \%$ of all pregnancies [1, 2] and is made based on additional tests such as serial determinations of chorionic gonadotrophin concentration and imaging examinations - ultrasonography [1-3]. Depending on the clinical presentation and results of ultrasonography, miscarriages can be divided into complete spontaneous miscarriage, and incomplete miscarriage, when the width of the echo of residual tissues in the uterine cavity exceeds $10 \mathrm{~mm}$ on ultrasonography and is accompanied by the presence of clinical symptoms such as vaginal bleeding and abdominal pain [4]. The other type of miscarriage is defined as retained products of conception (RPOC) and refers to the state when the gestational sac contains the embryo with crown-rump length (CRL) of $>7 \mathrm{~mm}$ but embryonic cardiac activity is invisible [3]. Empty gestational sac is diagnosed when the gestational sac with a diameter of $>25 \mathrm{~mm}$ and without an embryo is visible in the uterine cavity on ultrasonography [3]. 
When miscarriage is diagnosed, therapeutic decisions are made depending on the type of miscarriage, the presence and severity of clinical symptoms, as well as patient choice; the patient is informed about possible therapeutic options together with the advantages and disadvantages of each option [5-8]. Historically, a diagnosis of miscarriage resulted in immediate curettage of the uterine cavity in order to avoid complications associated with gestational tissues remaining in the uterine cavity such as hemorrhage, local or generalized infection, and proliferation of trophoblastic tissue leading to gestational trophoblastic disease $[5,6]$. In the literature, two methods of treatment are described. The first method is the classic approach based on curettage of the uterine cavity. It allows for the removal of gestational tissues from the uterine cavity and the direct collection of specimens for histopathological examination. The second one is based on pharmacological treatment with cytostatics, analogues of prostaglandins and/or selective estrogen receptor modulators [6, 7, 9-12].

The legitimacy of routine histopathological assessment of uterine products of miscarriage is currently under debate [13-23]. Some authors opt for routine histopathological examination of gestational tissues as a necessary supplement to the miscarriage therapy because it enables treatment maintenance in the case of a proliferative pathology of the trophoblast [13-19]. An additional argument for histopathological examination is the possibility to obtain guidance on the necessity of further tests (e.g., genetic tests) and help make the final diagnosis in cases with pregnancy of unknown location [15-18]. Other group of researchers claims that the routine histopathological examination has no justification, and recommended only in particular cases when ultrasound examination suggests features of trophoblast pathology or in patients with habitual miscarriages as well as when the results of the histopathologic examination are required for the diagnosis [7, 21-23]. According to NICE guidelines from 2014 regarding management of ectopic pregnancy and miscarriage, there is no evidence for the necessity of further monitoring and additional tests following miscarriage [24]. The Royal College of Pathologists recommends histopathological examination in late miscarriages, but the decision to conduct such an examination is left to the discretion of guidelines of local obstetric and gynecological associations [25]. Similar to previous institution, NHS England Standard Contract recommends a histopathological examination in cases of unexplained pregnancy loss after 12 weeks of gestation [26].

\section{Aim of the Study}

The aim of the study was to assess the diagnostic value of the histopathological examination results of miscarriage products in missed miscarriage and empty gestational sac in relation to the administered treatment — pharmacological induction of miscarriage vs. curettage of the uterine cavity.

\section{MATERIALS AND METHODS}

The retrospective analysis comprised 850 records from patients with a clinical and ultrasound diagnosis of missed miscarriage or empty gestational sac hospitalized in the 2nd Department of Gynecology and Obstetrics of the Medical University in Wroclaw, Poland, between 2014 and 2017. Patients with first-trimester pregnancies at admission were included. Cases with spontaneous inevitable miscarriage and well as incomplete and complete miscarriage. The study group was homogenous in terms of race and nationality. Pharmacological and/or surgical treatment was conducted taking into account patient preference. Pharmacotherapy included administration of $800 \mu \mathrm{g}$ of misoprostol a day (two doses of $400 \mu \mathrm{g}$ for 2 days). On the $3^{\text {rd }}$ day a transvaginal ultrasound was performed. The treatment was considered unsuccessful if residual tissues in the uterine cavity of $>10 \mathrm{~mm}$ were visible on ultrasonography; then patients were subjected to curettage of the uterine cavity. All patients were hospitalized until the treatment was successful.

All tissue specimens were obtained by qualified medical staff - midwives. They were first assessed macroscopically for the presence of tissues and next, after fixation of the specimens in a $10 \%$ solution of formalin, they were packed accordingly and sent to the Department of Pathomorphology and Oncological Cytology at Wroclaw Medical University, Poland, for histopathology. For histopathological evaluation, formalin-fixed and paraffin-embedded tissues were used. Paraffin blocks were cut into $4 \mu \mathrm{m}$-thick sections subsequently mounted on sialinized glass slides, which were then subjected to automated staining with hematoxylin and eosin in Sakura Tissue-Tek Prisma \& Film Slide Stainer and Coverslipper (Sakura Finetek Europe B.V., Alphen aan den Rijn, The Netherlands). Evaluation of slides was performed by means of light microscopy (Olympus BX51; Olympus America, Inc., Melville, NY). Results included information about the presence of fetal tissues, villi, maternal tissues - decidua, as well as other structures such as blood clots and autolyzed tissues.

Data from medical records such as parity, gestational age, and diagnosis, as well as the type of applied treatment and the way the material for histopathology was obtained, were statistically analyzed. Patients who did not achieve successful evacuation of tissues from the uterine cavity in the course of pharmacological treatment were subjected to the combination treatment - the first specimen was sampled during pharmacological treatment and the second during curettage of the uterine cavity. The combination treatment was administered to 497 initially treated with 
pharmacotherapy. In those cases, 2 specimens were collected for histopathology and both included into analysis. From 850 patients, ultimately 1128 results of histopathological tests were obtained. The results of histopathology were evaluated for their diagnostic value and classified into the following subgroups: subgroup 1 - high value specimen (the studied specimen included fetal tissues, and villi), and subgroup 2 - no-diagnosis (the studied specimen included maternal tissues - decidua, autolyzed tissues, blood clots but no fetal tissues and villi).

Data were collected in an Excel spreadsheet and then statistically analyzed using R Project for statistical computing $v$ 3.4.1. The data were presented as means (standard deviation) or median (range) and numbers (percentages) depending on their type and distribution. Two groups of categorical variables were compared with Pearson's chi-squared test. Differences were considered statistically significant at $p<0.05$

\section{RESULTS}

In the studied group of 850 women with the mean age of 32.7 years (range from 17 to 44 years of age), median parity was 1.94 (from 1 to 7). Mean gestational age at diagnosis was $8.8 \pm 1.9$ weeks of gestation and ranged from 6 to 12 gestational weeks. Overall, $18.9 \%$ of studied patients reported at least 1 miscarriage in the history (range from 1 to 5). In the study group, 746 (86\%) of women were diagnosed with missed miscarriage, while 110 (13\%) had empty gestational sac (Tab. 1).

Pharmacotherapy was given to 788 (92.7\%) patients. Of these, 291 (34.2\%) did not require further treatment, 497 (58.5\%) women were treated with combined therapy with pharmacotherapy followed by curettage of the uterine cavity due to the lack of efficacy of pharmacotherapy applied. Surgical treatment was performed as

\begin{tabular}{|l|l|l|}
\hline \multicolumn{3}{|l|}{ Table 1. Distribution of patient by diagnosis } \\
\hline Type of miscarriage & Number of cases & Percentage \\
\hline Missed abortion & 740 & $87.1 \%$ \\
\hline Blight ovum & 110 & $12.9 \%$ \\
\hline Total & 850 & $100 \%$ \\
\hline
\end{tabular}

Table 2. Distribution of patients by the type of treatment

\begin{tabular}{|l|l|l|}
\hline Type of treatment & Number of procedures & Percentage \\
\hline Pharmacotherapy only & 291 & $34.2 \%$ \\
\hline Surgery only & 62 & $7.3 \%$ \\
\hline $\begin{array}{l}\text { Combined treatment } \\
\text { (pharmacotherapy+surgery) }\end{array}$ & 497 & $58.5 \%$ \\
\hline Total & 850 & $100 \%$ \\
\hline
\end{tabular}

the initial method of choice in $62(7.3 \%)$ patients. Types of administered treatment are presented in Table 2.

In total, 1128 tissues specimens were collected from 850 patients. All 1128 specimens were divided into 2 groups: group A — specimens obtained in the course of pharmacological induction of miscarriage $(n=569)$ and group $B-$ specimens obtained in the course of curettage of the uterine cavity ( $n=559 ; 497$ results after the initial pharmacotherapy and 62 results treated with surgery as the method of choice) (Tab. 3).

Taking into account histopathological results, in the pharmacotherapy group (group A), high value specimens (subgroup 1) comprised 231 cases (40.59\%) while no diagnosis (subgroup 2) was obtained in 338 cases (59.4\%). Considering specimens obtained in the course curettage (group B), high value specimens (subgroup 1) were found in 364 (65.1\%) results while results that did not allow a diagnosis to be made (subgroup 2) were found in 195 cases (34.9\%). The difference was statistically significant $(p<0.05)$ based on Chi square test. Results of histopathological examination are summarized in Table 4.

A total of 4 cases $(0.5 \%)$ were diagnosed with molar pregnancy (2 complete molar pregnancies and 2 partial molar pregnancies). Those patients were initially subjected to pharmacotherapy, which was unsuccessful, and then to curettage of the uterine cavity. It is important to note that in those cases, specimens for histopathology were obtained solely after curettage because, after pharmacotherapy, patients failed to deliver specimens, or the histopathology gave a non-diagnostic result. As many as 497 women (63.1\%) required additional curettage after the initial pharmacotherapy due to its lack of effectiveness - defined as the presence of the echo of tissues of $>10 \mathrm{~mm}$ in the uterine cavity. In the present study, the efficacy of pharmacotherapy was $36.9 \%$. Efficacy of pharmacological treatment is presented in Table 5.

\begin{tabular}{|c|c|c|}
\hline Type of treatment & $\begin{array}{l}\text { Number of histopathological } \\
\text { results }\end{array}$ & Percentage \\
\hline Pharmacotherapy & 569 & $50.4 \%$ \\
\hline Surgical treatment & 559 & $49.6 \%$ \\
\hline Total & 1128 & $100 \%$ \\
\hline
\end{tabular}

Table 4. Value of histopathology results

\begin{tabular}{|l|l|l|}
\hline Value & Group A & Group B \\
\hline High value specimen & $231(40.6 \%)$ & $364(65.1 \%)$ \\
\hline No diagnosis & $338(59.4 \%)$ & $195(34.9 \%)$ \\
\hline Total & $569(100 \%)$ & $559(100 \%)$ \\
\hline
\end{tabular}


Table 5. Efficacy of pharmacological treatment

\begin{tabular}{|l|l|l|}
\hline Value & Number of procedures & Percentage \\
\hline Incomplete & 497 & $63.1 \%$ \\
\hline Complete & 291 & $36.9 \%$ \\
\hline Total & 788 & $100 \%$ \\
\hline
\end{tabular}

\section{DISCUSSION}

In the last few decades, an increase in the frequency of pharmacological management of spontaneous miscarriage, including missed miscarriage and empty gestational sac, has been observed in many medical centers [4-6, 12]. The advantages of this option are obvious, as this method is non-invasive and well-accepted by patients, does not require anesthesia, and results in a lower percentage of short- and long-term complications in comparison to curettage $[5,6,27,28]$. However, it is associated with longer hospitalization; increased and prolonged blood loss; increased demand for emergency intervention due to complications of pharmacotherapy; and most of all with lower efficacy $[5,6,9$, 27-29]. In the present study, the pharmacotherapy success rate was $36.9 \%$; the efficacy reported by other authors differs and ranges from $47 \%$ to $91.5 \%[9,10,13,30,31]$. Our analysis revealed that the majority of patients subjected to pharmacotherapy, i.e., $63.1 \%$ of them, required subsequent curettage of the uterine cavity for evacuation of biological tissues or debris from the uterus. Sotiriadis et al. [30] reported that pharmacological treatment was less effective than curettage of the uterine cavity ( $66 \%$ vs $100 \%$, respectively); however, they observed higher efficacy of pharmacotherapy than is presented in our study. The present study revealed that in case of pharmacological treatment, we were able to collect high value diagnostic specimens in $40.6 \%$ of specimens analyzed. In the study performed by Petersen et al. [27], only $22.8 \%$ of cases treated with pharmacotherapy were able to deliver specimens for histopathology; however, in this study specimens were not assessed for their quality and diagnostic value. Converse results are presented by Heath et al. [21] who reports that $99.5 \%$ of patients treated with pharmacotherapy delivered specimens for histopathology that allowed a diagnosis to be made. It is worth noting that this study employed different procedure based on different dosing schedule and combined therapy with misoprostol i mifepristone. In the literature, there is a lack of data evaluating a diagnostic value of specimens collected in the course of miscarriage treatment depending to the method of treatment applied. In the present study, the diagnostic value of the material obtained in the course of miscarriage treatment was presented depending on the method of treatment. A statistically significant difference in diagnostic value was shown between cases treated with pharmacotherapy and curettage of the uterine cavity.
In the literature, there is an ongoing debate on the legitimacy of the routine histopathological examination of tissues obtained after miscarriage [13, 15-18, 20-23]. One of the aims of the histopathological examination of gestational tissues is the detection of trophoblast pathology such as gestational trophoblastic disease, molar pregnancy, and choriocarcinoma. Based on data from the literature, the incidence of trophoblastic disease is estimated to range from 0.57 to 1.1 per 1,000 pregnancies [30, 32] The local incidence of gestational trophoblastic disease may be the factor that is worth considering when making a decision to conduct a routine histopathologic examination of obtained tissues. This can also affect the rate of high diagnostic value of specimens, e.g. the incidence of hydatidiform mole is rated at 1 in 80 pregnancies in Asia, whereas 1 in 500-1500 pregnancies in the countries of Western Europe and 1 in 452-1098 pregnancies in Saudi Arabia. The incidence of this complication decreases over time with improvement in health care [7]. Biscaro et al. [33] revealed that the frequency of detection of molar tissues was $2.2 \%$ in specimens obtained during curettage of the uterine cavity. In the present study, a lower frequency of $0.5 \%$ was observed and no case of choriocarcinoma was found when analyzing specimens obtained in the course of curettage.

Other information from histopathological examinations can play a role in the diagnostic process, such as the detection of chromosomal aberrations in fetal tissues and other facts helpful for determining the location of pregnancies of unknown location. Those should be considered as further arguments for conducting routine histopathological examinations $[13,15-18,20]$. Heath et al. claim that the frequency of disorders diagnosed by histopathological examination is low and does not support routine tests. It may be considered as a diagnostic extension solely in questionable cases. The frequency of trophoblast disorders reported by Heath et al. [21] was as low as $0.1 \%$. Similarly, Alsibiani at al. [7] claims that histopathological examination should be performed in selected cases. However, in light of the serious consequences rooted in the delay in diagnosis or misdiagnosis of women who did not have such an examination - and thus leading to a delay in the administration of proper therapy - many authors claim that the histopathological examination still constitutes an obligatory element which supplements the diagnosis and treatment of early pregnancy failure $[13,15,19,28]$. We agree with this view due to medical and legal consequences resulting from undetected trophoblast diseases or delayed diagnosis - histopathological assessment should be performed in every case of miscarriage regardless of the incidence of those diseases as well as results of imaging examinations and clinical symptom.

\section{CONCLUSIONS}

Tissue specimens of high diagnostic value are obtained significantly more often during surgical treatment of mis- 
carriage than during pharmacotherapy. Histopathological results of no diagnosis are more often associated with the specimens obtained in the course of pharmacological procedure in comparison to invasive procedure. We recommend conducting histopathological examination in every case of miscarriage regardless of the mode of therapy applied due to medical and legal consequences resulting from undetected trophoblast diseases or delayed diagnosis despite their rare incidence. When trophoblast pathology is suspected, obtaining tissue specimens for histopathology is recommended, which can be ensured by invasive treatment.

\section{REFERENCES}

1. Poland BJ, Miller JR, Jones DC, et al. Reproductive counseling in patients who have had a spontaneous abortion. Am J Obstet Gynecol. 1977; 127(7): 685-691, indexed in Pubmed: 848521.

2. WARBURTON D, FRASER FC. SPONTANEOUS ABORTION RISKS IN MAN: DATA FROM REPRODUCTIVE HISTORIES COLLECTED IN A MEDICAL GENETICS UNIT. Am J Hum Genet. 1964; 16: 1-25, indexed in Pubmed: 14131871.

3. Doubilet PM, Benson CB, Bourne T, et al. Society of Radiologists in Ultrasound Multispecialty Panel on Early First Trimester Diagnosis of Miscarriage and Exclusion of a Viable Intrauterine Pregnancy, Society of Radiologists in Ultrasound Multispecialty Panel on Early First Trimester Diagnosis of Miscarriage and Exclusion of a Viable Intrauterine Pregnancy. Diagnostic criteria for nonviable pregnancy early in the first trimester. N Engl J Med. 2013; 369(15): 1443-1451, doi: 10.1056/NEJMra1302417, indexed in Pubmed: 24106937.

4. Lemmers $M$, Verschoor MAC, Bossuyt PM, et al. MisoREST study group. Cost-effectiveness of curettage vs. expectant management in women with an incomplete evacuation after misoprostol treatment for first-trimester miscarriage: a randomized controlled trial and cohort study. Acta Obstet Gynecol Scand. 2018; 97(3): 294-300, doi: 10.1111/aogs.13283, indexed in Pubmed: 29266169.

5. Kim C, Barnard S, Neilson JP, et al. Medical treatments for incomplete miscarriage. Cochrane Database Syst Rev. 2017; 1: CD007223, doi: 10.1002/14651858.CD007223.pub4, indexed in Pubmed: 28138973.

6. Demetroulis C, Saridogan E, Kunde D, et al. A prospective randomized control trial comparing medical and surgical treatment for early pregnancy failure. Hum Reprod. 2001; 16(2): 365-369, doi: 10.1093/humrep/16.2.365, indexed in Pubmed: 11157836.

7. Alsibiani SA. Value of histopathologic examination of uterine products after first-trimester miscarriage. Biomed Res Int. 2014; 2014: 863482, doi: 10.1155/2014/863482, indexed in Pubmed: 25054151.

8. Tomasik P, Zwierzchowska A, Barcz E. Assessment of patient acceptability of medical treatment in case of non-viable first trimester pregnancy. Ginekol Pol. 2015; 86(5): 383-387, indexed in Pubmed: 26117978.

9. Luise $C$, Jermy $K$, May $C$, et al. Outcome of expectant management of spontaneous first trimester miscarriage: observational study. BMJ. 2002; 324(7342): 873-875, doi: 10.1136/bmj.324.7342.873, indexed in Pubmed: 11950733.

10. Jurkovic D, Ross JA, Nicolaides $\mathrm{KH}$. Expectant management of missed miscarriage. Br J Obstet Gynaecol. 1998; 105(6): 670-671, indexed in Pubmed: 9647160.

11. Bagratee JS, Khullar V, Regan L, et al. A randomized controlled trial comparing medical and expectant management of first trimester miscarriage. Hum Reprod. 2004; 19(2): 266-271, doi: 10.1093/humrep/deh049, indexed in Pubmed: 14747165.

12. Ngai SW, Chan YM, Tang OS, et al. Vaginal misoprostol as medical treatment for first trimester spontaneous miscarriage. Hum Reprod. 2001; 16(7): 1493-1496, doi: 10.1093/humrep/16.7.1493, indexed in Pubmed: 11425836.

13. Novak RW, Malone JM, Robinson HB. The role of the pathologist in the evaluation of first trimester abortions. Pathol Annu. 1990; $25 \mathrm{Pt} 1$ : 297-311, indexed in Pubmed: 2404247.
14. Rashid P. The role of histopathological examination of the products of conception following first-trimester miscarriage in Erbil Maternity Hospital. Zanco Journal of Medical Sciences. 2017; 21(3): 1938-1942, doi: 10.15218/zjms.2017.054.

15. Tasci $Y$, Dilbaz S, Secilmis O, et al. Routine histopathologic analysis of product of conception following first-trimester spontaneous miscarriages. J Obstet Gynaecol Res. 2005; 31(6): 579-582, doi: 10.1111/j.14 47-0756.2005.00341.x, indexed in Pubmed: 16343264.

16. Yap SJ, Watts JC, Faithfull TJ, et al. Is tissue an issue? Current practice and opinion in Western Australia for routine histopathology on products of conception. Aust N Z J Obstet Gynaecol. 2014; 54(5): 493-496, doi: 10.1111/ajo.12238, indexed in Pubmed: 25287569.

17. Szulman AE, Ma HK, Wong LC, et al. Residual trophoblastic disease in association with partial hydatidiform mole. Obstet Gynecol. 1981; 57(3): 392-394, indexed in Pubmed: 6258115.

18. Bagshawe KD, Lawler SD, Paradinas FJ, et al. Gestational trophoblastic tumours following initial diagnosis of partial hydatidiform mole. Lancet. 1990; 335(8697): 1074-1076, indexed in Pubmed: 1970378.

19. Hinshaw K, Fayyad A, Munjuluri P. The management of early pregnancy loss. http://www.jsog.org/GuideLines/The_management_of_early_ pregnancy_loss.pdf (25.04.2018).

20. Fram KM. Histological analysis of the products of conception following first trimester abortion at Jordan University Hospital. Eur J Obstet Gynecol Reprod Biol. 2002; 105(2): 147-149, indexed in Pubmed: 12381477.

21. Heath V, Chadwick V, Cooke I, et al. Should tissue from pregnancy termination and uterine evacuation routinely be examined histologically? BJOG. 2000; 107(6): 727-730, indexed in Pubmed: 10847227.

22. Jauniaux E, Kadri R, Hustin J. Partial mole and triploidy: screening patients with first-trimester spontaneous abortion. Obstet Gynecol. 1996; 88(4 Pt 1): 616-619, indexed in Pubmed: 8841229.

23. Gal A, Stenning H. Pitfalls in the diagnosis of ectopic pregnancy. Med J Aust. 1985; 143(9): 411-412, indexed in Pubmed: 3903455.

24. NICE. Ectopic pregnancy and miscarriage: diagnosis and initial management. Clinical guideline [CG154]. https://www.nice.org. uk/guidance/cg154/resources/surveillance-report-2017-ectopic-pregnancy-and-miscarriage-diagnosis-and-initial-management-2012-nice-guideline-cg154-4367146717/chapter/Surveillance-decision 2012 (30.07.2018).

25. Cox P, Evans C. Tissue pathway for histopathological examination of the placenta. http://www.rcpath.org/publications-media/publications/datasets/tissue-pathway-placenta (30.06.2018).

26. NHS Commissioning Board. E12/S/b - 2013/14 NHS Standard Contract for Perinatal Pathology. https://www.england.nhs.uk/wp-content/uploads/2013/06/e12-perinatal-path.pdf 2013 (30.06.2018).

27. Petersen SG, Perkins AR, Gibbons KS, et al. The medical management of missed miscarriage: outcomes from a prospective, single-centre, Australian cohort. Med J Aust. 2013; 199(5): 341-346, indexed in Pubmed: 23992191.

28. Sur SD, Raine-Fenning NJ. The management of miscarriage. Best Pract Res Clin Obstet Gynaecol. 2009; 23(4): 479-491, doi: 10.1016/j.bpobgyn.2009.01.014, indexed in Pubmed: 19303819.

29. Petrou S, Trinder J, Brocklehurst $P$, et al. Management of miscarriage: expectant, medical, or surgical? Results of randomised controlled trial (miscarriage treatment (MIST) trial). BMJ. 2006; 332(7552): 1235-1240, doi: 10.1136/bmj.38828.593125.55, indexed in Pubmed: 16707509.

30. Sotiriadis A, Makrydimas G, Papatheodorou S, et al. Expectant, medical or surgical management of first-trimester miscarriage: a meta-analysis. Obstet Gynecol. 2005; 105(5 Pt 1): 1104-1113, doi: 10.1097/01. AOG.0000158857.44046.a4, indexed in Pubmed: 15863551.

31. Graziosi GCM, Bruinse HW, Reuwer PJH, et al. Misoprostol versus curettage in women with early pregnancy failure: impact on women's health-related quality of life. A randomized controlled trial. Hum Reprod. 2005; 20(8): 2340-2347, doi: 10.1093/humrep/dei019, indexed in Pubmed: 15831508.

32. Kitange $B$, Matovelo $D$, Konje $E$, et al. Hydatidiform moles among patients with incomplete abortion in Mwanza City, North western Tanzania. Afr Health Sci. 2015; 15(4): 1081-1086, doi: 10.4314/ahs.v15i4.5, indexed in Pubmed: 26958007.

33. Biscaro A, Silveira SK, Locks Gd, et al. [Frequency of hydatidiform mole in tissue obtained by curettage]. Rev Bras Ginecol Obstet. 2012; 34(6): 254-258, indexed in Pubmed: 22801599. 